\title{
EDITORIAL
}

\section{La educación con base en la ciencia: del mito a la realidad}

\section{Jorge Eduardo Duque}

B.Sc., M.Sc., Ph.D., profesor, Departamento de Ciencias Básicas Biológicas, Universidad Autónoma de Manizales; profesor, Departamento de Ciencias Básicas, Universidad de Caldas, Manizales, Colombia.

Correspondencia: jduqueparra@yahoo.com.mx

"Si la verdad, si todas las verdades no están sujetas al examen del "ensayo y el error", si no existe una libertad que permita a los hombres cuestionar y compulsar la validez de todas las teorías que pretenden dar respuesta a los problemas que enfrentan, la mecánica del conocimiento se ve trabada y este puede ser pervertido. Entonces, en lugar de verdades racionales, se entronizan mitos, actos de fe, magia".

Mario Vargas Llosa

La palabra "ciencia" se asimila a saber o conocimiento y se puede definir como todo lo que nos permite predecir las cosas, con base en los resultados que se obtienen derivados de la investigación. La ciencia se diferencia de la pseudociencia porque no permite predecir, aunque millones de seres humanos adoptan este tipo de falso conocimiento, como es el caso de la astrología, la quiromancia, la brujería, las curaciones milagrosas y la charlatanería, entre otras.

La ciencia, a diferencia de los mitos y la pseudociencia, permite y explora el misterio, pero no la magia; estudia los misterios naturales, pero no los hechizos ni la brujería, ni los milagros baratos o caros, y aunque los seres humanos tenemos apetito de maravillas -como una especie de apetito poético que la auténtica ciencia debiera alimentar-, dicho apetito está siendo asumido con gran frecuencia por el afán de lucro de los charlatanes, por los proveedores de la superstición, de lo paranormal, de las deidades y la astrología, vínculos antiquísimos que debemos ir superando con base en el conocimiento logrado mediante la ciencia. 
La ciencia se desarrolla para tratar de reconocer las leyes que rigen los eventos del universo en todas sus escalas, sean estas macroscópicas, microscópicas, moleculares, atómicas o subatómicas. De ese estudio surgen teorías que permiten comprender mejor los datos a partir de un pequeño número de leyes y ecuaciones, cuya aplicación llega, incluso, a las ciencias abstractas, tales como la ética o la estética, áreas del saber construidas con conceptos no accesibles mediante los órganos sensoriales, pero sí generadas por la actividad del cerebro: la mente. Sin embargo, dentro de un concepto de ciencia puro, estas ciencias abstractas cumplen todos los requisitos de ciencia y tienen importantes funciones dentro de nuestra cultura, permitiéndonos crear patrones para la convivencia social mediante razonamientos lógicos.

Otras ciencias son las que buscan el conocimiento de las causas de los eventos naturales, a los cuales debe el ser humano su papel de dominador de la tierra; estas tienen por objeto cuantificar todo lo que puede ser cuantificable y hacer cuantificable todo lo que no lo es. Por ello, los científicos tienen una misión importante: descubrir y comprender las razones por las cuales suceden las cosas. Esta tarea se logra mediante el método científico, que consiste en el desarrollo de una hipótesis, una experimentación, una verificación final de la veracidad de esa hipótesis y una discusión para generar una conclusión; no obstante, puede que la conclusión sea que la hipótesis era equivocada, esto siempre dentro del marco de la búsqueda de una verdad que no es definitiva: sólo es transitoria. Por lo tanto, los científicos deben asegurarse de que esa verdad saldrá a la luz al final, por medio de la objetividad otorgada por dicho método científico, sin un dogmatismo a ultranza, pues la arrogancia de creer que se posee la única verdad hace olvidar con demasiada frecuencia la humildad y la precaución, elementos característicos de la ciencia.

La ciencia no es para obtener gloria, ni premios o recompensas, es por el placer de hacerla; se realiza por el puro placer de descubrir cómo funciona el mundo y nosotros en él, y es el placer implícito, el premio por descubrir y en la excitación del descubrimiento, el observar que otras personas utilizan dicho trabajo para mejorar el mundo o, de momento, para comprenderlo. La ciencia, así, pretende constituir un mundo que sea una representación simbólica del mismo, de las experiencias cotidianas. Las leyes que se encuentran en esta búsqueda científica, que a veces parecen definitivas, siguen funcionando y luego de repente, en algún momento, se puede encontrar que eran erróneas; entonces, se deben investigar las condiciones en las que sucedió el cambio. En eso consiste la ciencia, pero ella no tiene respuestas a todas las preguntas maravillosas acerca de quiénes somos, de dónde venimos, 
a dónde vamos, cuál es el significado del universo y mucho más. Si en la ciencia se genera alguna verdad, no lo sabremos, pues estaríamos tratando de descubrir algo que posiblemente sea falso en algún momento o, al menos, parcialmente falso. Una parte de la aventura de la ciencia está en tratar de encontrar una limitación en cualquier dirección y extender la imaginación humana hasta donde nos sea posible, usando un marco de referencia cultural que tiende a homogeneizarse por el conocimiento global de las diversas culturas.

Antes de empezar una investigación no se puede saber la respuesta, así que los investigadores empiezan estando inseguros de cuál es la respuesta, que surge, por tanto, de la duda y la incertidumbre, elementos necesarios para empezar una investigación, aunque una pregunta bien planteada parece llevar implícitamente la respuesta. Si ya se conociera la respuesta al interrogante, no habría necesidad de reunir ninguna evidencia sobre ello. La próxima acción sería buscar evidencia y, con el método científico como herramienta, se empieza con ensayos, reuniendo ideas para tratar de conseguir una consistencia lógica entre las diversas cosas que se conocen y comparándolas para, posiblemente, llegar a mejorar la hipótesis, esto, mediante la experimentación.

El científico es el profesional que tiene mucha experiencia sobre interrogantes de su área del conocimiento, especialmente con la ignorancia, la duda y la incertidumbre de lo que conoce; mas, una vez ha iniciado la búsqueda de la evidencia, tiene que juzgarla y, en ello, no es correcto que tome solo lo que a él le gustaría considerar, sino que debe considerar la mayor cantidad de evidencia que pueda encontrar. El científico habrá de tratar de mantener cierta objetividad sobre el asunto investigado, pues el entorno en que vivimos es activo e intensamente acientífico, ya que la gente vive de muchos mitos que lo alejan de la realidad, como la supuesta existencia de la telepatía, la acciones bienhechoras de las deidades o las curaciones por la fe, entre muchas cosas que merecen ser investigadas. Pero, si estos mitos son puestos en debate y se plantearan experimentos que permitieran demostrarnos que lo indicado es cierto, podría ser que la astrología fuera correcta, que ir al médico un día que se dé alineación planetaria fuera mejor que ir otro día, que una persona pueda curarse por un milagro en $X$ o Y iglesia, pues estas, quizá, posean ciertas características particulares que beneficien a personas que sufren de diversas enfermedades y que los afectan en su salud: las gotas oftálmicas de las religiosas W que eliminan las cataratas. Si eso fuera cierto, debería ser investigado, y muy intensamente, para mejorar el entendimiento de los eventos que allí se generan y dar un acceso más racional a las creencias de las personas, aprovechando esos beneficios para la salud y el bienestar humano. 
Ciencia no significa certeza, pues en ella se generan incertidumbres, por lo que un científico nunca estará seguro y sus enunciados serán meras aproximaciones con diferentes grados de certeza. Por ello, debemos dejar sitio para la duda, si no, no habría progreso y aprendizaje, y en consecuencia, no habría ciencia, pues todo sería estático. No obstante, los enunciados de la ciencia no tratan de lo que es cierto y lo que no es cierto, sino que son enunciados sobre lo que se conoce con diferentes grados de certeza, ya que todos los conceptos de la ciencia se encuentran en alguna zona intermedia de una escala graduada, pero, en ninguno de los extremos: la falsedad absoluta o la verdad absoluta. A pesar de ello, la gente busca certeza, aunque la mayoría de nuestras acciones están basadas en un conocimiento incompleto y realmente no lo sabemos todo.

Los seres humanos de todas las épocas han tratado de encontrar el secreto de las cosas, pero esto no se ha logrado y muchas respuestas son diferentes. La ciencia deja puertas entreabiertas a lo desconocido, pero solo medio abiertas, para no dar lugar a la superchería o las doctrinas por fe que tanto alejan y engañan a nuestra población; aunque la ciencia actual, a pesar de estar bien fundadas muchas de sus aproximaciones como conclusiones, no tiene el derecho de hipotecar el porvenir, porque nuestras afirmaciones de hoy no podrían ir más allá de las revelaciones de los métodos del momento que el ser humano del futuro podría considerarlos obsoletos.

Aunque algo se reconoce de la ciencia, es importante aclarar que hay conocimiento que no entra dentro de su campo. Por ejemplo, el arte, que no es considerado ciencia esencialmente porque las obras de arte son, por lo general, el resultado de la actividad creativa de un solo individuo y en la ciencia, aunque algo se origine en la acertada intuición de una sola persona, inmediatamente pasa a ser una obra colectiva que va profundizándose y ampliándose a medida que los estudios llevan a nuevos conocimientos; esto es característica de una disciplina dinámica y cambiante, aun cuando evolucione con cierta lentitud, y en ella se invierte un gran capital en equipos y técnicas especializadas que potencian el trabajo en equipo. En últimas, la ciencia es social.

La ciencia, como tal, estará siempre sometida a discusiones, correcciones, modificaciones, refinamientos, reconsideraciones y visiones revolucionarias. Para unirse a la ciencia y poder disfrutar de sus visiones, hay que pagar una elevada cuota de ingreso hecha de esfuerzos, en especial, el de desligarnos de los mitos y deidades. La ciencia consiste en agrupar hechos de modo que puedan deducirse de ellos 
leyes o conclusiones generales, es decir, teoría científica, que no serían muy consistentes si no hubiera experimentos capaces de refutarla concluyentemente.

No hay duda de que la ciencia actual será derrocada en un futuro, pero no por anécdotas casuales, por actuaciones en televisión o comentarios sin razonamiento, sino por una investigación cada vez más rigurosa, repetida, rediseñada y disecada. Cuando se llegue a esos momentos, la ciencia dejará de ser una mera curiosidad, para convertirse en una necesidad en la que la disponibilidad de información científica esencial podrá significar la diferencia entre la salud y la enfermedad, entre la vida y la muerte.

"Donde la ignorancia es una bendición, es una locura ser sabio".

Thomas Gray 